\title{
Desktop VR Systems - A Distance Learning Method and Technology
}

\author{
M. Travassos Valdez \\ Departamento de Electrotecnia \\ Instituto Superior de Engenharia de \\ Coimbra (ISEC) \\ Coimbra, Portugal \\ valdez@isec.pt
}

\author{
C. Machado Ferreira \\ Departamento de Electrotecnia \\ Instituto Superior de Engenharia de \\ Coimbra (ISEC) \\ Coimbra, Portugal \\ cmacfer@isec.pt
}

\author{
F. P. Maciel Barbosa \\ Faculdade de Engenharia \\ Universidade do Porto \\ \& INESC TEC \\ Porto, Portugal \\ fmb@fe.up.pt
}

\begin{abstract}
This paper discusses the effective contribution of a Learning Object (LO) to teach circuit theory based on research conducted with students of higher education, and their interaction with a teacher of Electronics. From the results of such research, it is pointed out which features one wants in the LO so that it successfully promotes learning. It is in this perspective that this work was conceived having as goal the development of LO, admitting that this may be a possible alternative to represent models of interactions, which occur within the area, thereby improving understanding of physical concepts, in particular those involved with the subject of electrical circuits. It has also as objective to characterize the learning process through a series of situations that are replicated leading to a set of behaviors from the students. It is assumed that the use of this tool can lead to acquiring a specific set of skills, a better practice and meaningful learning.
\end{abstract}

Keywords-- circuit theory; electrical circuits; interactive circuit; learning object

\section{INTRODUCTION}

The use of information technology as an education support is widespread, and there is varied software developed for educational purposes, the designated Educational Software ES. This is playing an ever greater role in education.

For several authors, all software can be considered an ES since it uses a methodology that contextualizes the teachinglearning process. Quality is the main aspect to be taken into account in choosing this type of software because, nowadays, the market is being increasingly provided with numerous applications and products with the most varied resources.

When one uses an ES, it is extremely important for the teaching process to use good pedagogical strategies as well as good quality materials. There are two important aspects in an ES: one is to know the system (usage) and the other is to learn to use it (cognitive development) as both are directly related in the function of man/machine interaction. To choose it for an educational institution, one must plan properly thinking about tools and processes and the team that is responsible for the implementation of the application in order to get software that is appropriate for the institution to provide an effective teaching quality.
Looking for educational software is associated with the ability to meet the requirements of interaction of users but no less important, is the ability to promote learning [1].

A computer simulation is an efficient technique for practical work applications. These simulations minimize the concerns of teachers in relation to time, costs or risks that involve the choice of inappropriate, inefficient, or potentially dangerous experimental strategies.

Learning objects (LO) using conceptual text, animation and interactive concept maps are called inclusive. Inclusive education is a process that extends to all students, aiming at personal growth, satisfaction and social integration of all. This is a restructuring of culture and practices experienced in schools so that they respond to diversity and can meet the needs of individual students [2].

The possibility to test different ways to monitor the temporal evolution of cause-and-effect relationships, to visualize concepts from different points of view and prove hypotheses, makes the animations and simulations a powerful tool to awaken new ideas, relate concepts, arouse curiosity and solve problems. These interactive activities offer opportunities for exploration of scientific phenomena and concepts, often impractical or nonexistent in schools, for economic and security reasons and allow experiments to be performed outside the classroom [3].

Among the numerous contexts in which virtual testing can be applied, this paper refers to systems of circuit theory, more specifically, to laboratory practice focused on teaching and learning in this area of knowledge. This choice was made from observing that a laboratory needs attendance, measures and instrumentation, which relate primarily to the question of access to the means and equipment to carry out the laboratory practice. So, it was established as a purpose for the work the use of virtual experimentation to carry out laboratory practice and also as an alternative tool to meet the needs of access to the means and equipment of a specific Instrumentation and Measurements lab.

\section{Methodological Procedures}

The main objective of this work was the development of an LO for teaching circuit theory. In this perspective, steps were taken for developing a LO: pedagogical design, preparation of 
courses, production of the object itself and teacher's Guide (Figure 1).

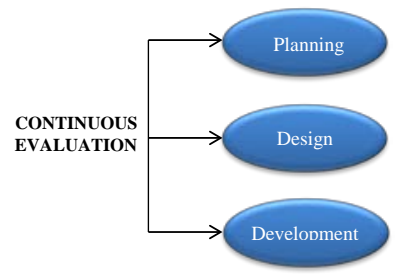

Figure 1 - The design and development model

One of the proposed solutions was the development of digital resources (such as video, animation, simulation, etc.) to allow teachers and students to explore specific concepts in circuit theory [4-5].

\section{A. Objectives of educational Software (SE)}

Whereas this LO is nothing more than a sequence of teaching tools that aim at leading the student to learn the physical concept and mathematical relationships involved, the methodology that was used in this research work was Didactic engineering [6].

To introduce the subject circuit theory, the student is confronted with a situation in which he interacts with the functionality of one or more equipment/devices or assemblies of electrical circuits [7-8]. From there, through the object, the students' curiosity is aroused in order to know how is the process of using the device chosen works. So, a sequence of interactive questions is triggered to lead students to understand it.

According to the contents of Circuit Theory, there is a set of laboratory experiments to provide the student/user with training and knowledge of circuit theory analysis in measurements and instrumentation. The goals are to provide the technical knowledge to analyze electrical circuits of direct or alternating current and to know and understand the various parameters of an electrical circuit: current, voltage, power, energy, power factor, etc.

Every experiment must supply technical/scientific knowledge in order to provide the student/user with experimentation in the syllabus. Virtual trials do not have to be sequential although the sequence of work can help to construct cognitive models required to learn about the full contents of the syllabus.

At the end of each virtual simulation, it is expected that the student is able to enter a real laboratory and perform the same work, without feeling any negative impact or maladjustment in relation to the real environment.

In this case, the idea was to build a 3D lab environment (Measures and Instrumentation) where the equipment and components can be seen and manipulated. The project was to build simple electrical schematics that later can be changed in values, presenting new results. The design features a set of menus and submenus to support the experiments [9].

\section{Virtual reality technologies}

VR systems can be generally classified into four categories, which are determined by their display technology: immersive, semi- immersive, designed and desktop.
As described by Sulbaran, VR tools development can be organized into three main groups [10]: Application Programming Interfaces (API), Software Development Kits (SDK) and authoring tools.

Desktop VR systems display their virtual environments on a conventional PC monitor and the interaction is usually achieved by using the mouse and keyboard [11]. However, these systems can offer support with other visual and interaction devices as the "shutter glasses" and "joysticks", to name just a few. In contrast to the systems described above, the VR desktop offers a much simpler, versatile and less expensive method to develop a VR system although it is achieved at the expense of a less immersive experience.

The software used to achieve the proposed objective was essentially 3D Max, VizUp and WireFusion @ 5.0. The general idea was to create a three-dimensional model (3ds Max, Maya, Cinema 4 D, SketchUp, Blender, LightWave or any other 3D tool), reduce the size of the $3 \mathrm{D}$ objects with VizUp and then export to WireFusion ${ }^{\circledR} 5.0$ [12-14].

In WireFusion, there will be the possibility of adding some interactivity and/or animations. However, any animation must be built on the source program of the 3D model. The last step was the production of interactive contents and the introduction of the presentations on the web, using HTML5, CSS3 and JavaScript, as offline presentations [14].

The application of VR presented in this work used a WireFusion ( ${ }^{\mathrm{B}} 5.0$ authoring tool that allowed the use of an educational license for a relatively short time and cost. This was a significant factor in the choice of this particular application for the development of VEMA (Virtual Electric MAnual). In addition, the Wirefusion does not generate images or 3D models; instead, the application has created a collection of 3D objects, images, animations, 3D meshes and sounds on a separate program and imported them into Wirefusion [14].

The learning object used in this work is composed by the equipment and the software application available to students in the laboratory. Most of the laboratory objects constructed were modeled with the software of Autodesk ${ }^{\circledR}$ 3ds Max ${ }^{\circledR}$. The 3D animations were also created directly in this tool, as well as the animation of cameras and lights. The data of the animation created were included as it is exported to VRML.
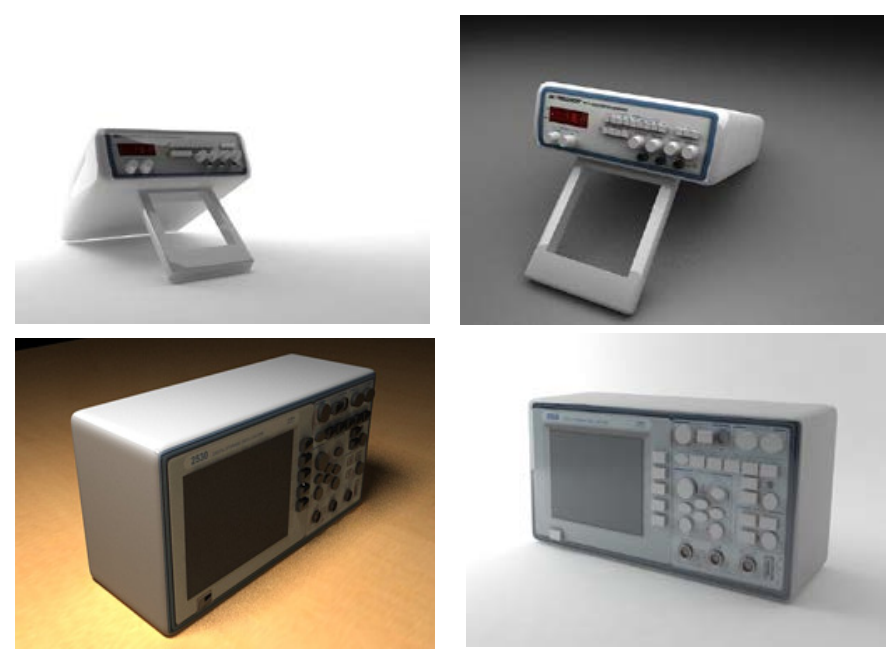

Figure 2 - Equipment, Signal generator and Oscilloscope (3ds Max) 
In Figure 2, images of some rendered objects constructed in 3ds Max can be observed, which constitute some of the equipment required in the experiments.

\section{A. Description of the type of educational software}

This paper presents an overview of the systems and tools of development of VR, focused on the software used in this prototype model, with the design process of a VR desktop prototype, Virtual Electric MAnual - VEMA. This was developed to demonstrate how the VR technology can be applied to an engineering unit and used to enhance security and resourcefulness in using electrical equipment [15].

From the educational point of view VEMA is not seen as a substitute of the traditional teaching methods, but only as a supplementary learning resource that can significantly improve the students' understanding and motivation. VEMA has the potential to involve students and present issues that can be investigated and resolved in their own time. This provides an incentive to students to become more active in their own learning in an environment that relates to the problem.

Engineers could use the application to exemplify some standard aspects. VEMA may also be used as an application of continuous professional development for Technological Specialization courses (TSC).

The fundamental goal of VEMA was to develop a prototype of a VR simulator to demonstrate the potential benefits of combining virtual reality to improve learning in the built environment and the concept of measurement in electrical circuits.

The potential target market for which the VR system can add some value includes engineering students, the general public and eventually electrical services and trainers that can, perhaps, benefit from the instructions contained in the virtual electric manual [15-16].

The initial development phase of the application required a construction of 3D models that exist usually in a measurements and instrumentation laboratories, using a conventional 3D modeling software (Figure 3).

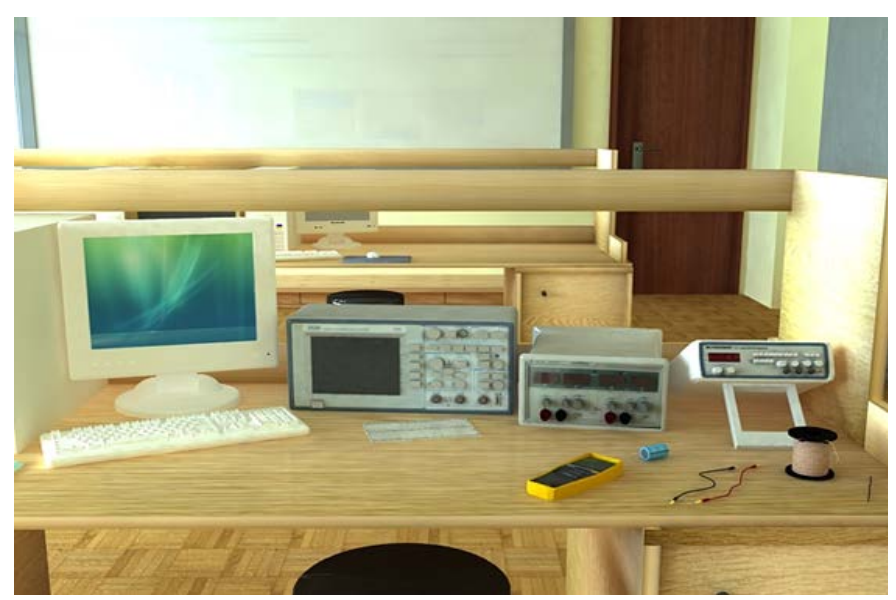

Figure 3 - Virtual laboratory environment created for the VEMA application

Figure 3 shows the interior of the laboratory setting with the layout of the workbench and the desired equipment. In this image the AutoCAD software "memorized" the indoor lab scenario plan accompanies the countertop plan, as an Xref.
3D Studio Max modeling geometric detail has been sacrificed to ensure the optimization of software rendering capabilities in real time, which could be adversely affected by the complex geometry and excessive texture sizes.

Usability studies of virtual environments have demonstrated that users tend not to identify or that they are oblivious of what is interactive or not. Making sure that the appliances are clear potentially improves interactive usability and helps in preventing students' frustration that, ultimately, can reduce the effectiveness of the application, as a training tool.

Various interactive scenes were developed to illustrate this point, using a Measurements and Instrumentation laboratory as virtual environment (Figure 4).

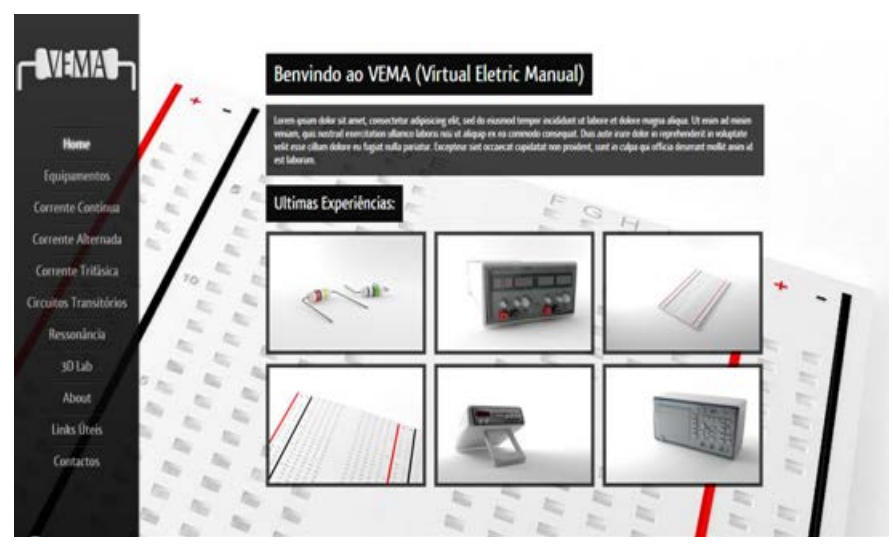

Figure 4 - Home page of VEMA

The menus on the left side of the screen are the keys where the desired experience can be selected by the students (Figure 4). With them, students can open different windows. Some unusual functions of the devices are not implemented.

Inside the simulator, the student can "walk" on the virtual laboratory facility and interact or simulate a value in any of the interactive devices, such as a power supply, resistors, etc. By varying these parameters the circuit is automatically updated and the student can instantly see the impact of choices.

In order to provide students with the highest degree of realism, models were set for the VEMA application: compliance with appropriate main electrical measures and instrumentation laboratories; visual representation of apparatus, equipment or electric mounts in the built environment; simulation and representation of the functionality of the assembling of appliances and equipment; appropriate theoretical standards leading electrical circuits. In addition, the VEMA application has to ensure the supply of interactivity, be intuitive and provide accessibility of the application in a wide range of platforms.

The application of the VEMA prototype consists, therefore, in experimental interactive scenes. A user interface allows the student to get in and out of each scene in an intuitive way.

\section{CONCLUSION}

Familiarity with the virtual environment can enable students to become quickly absorbed in small electrical projects. This way, the student can easily identify the parameters involved and thus develop a greater familiarity with 
the possibility to learn to design an electrical circuit with more confidence and safety [17].

The adoption of a circuit simulator "direct current" as a pedagogical instrument is a student-centered approach and moves from conventional learning techniques to a form of internship where students can self-learn, investigate results of data reached in their own convenient timing. The use of a training tool, through virtual reality, to educate students, and users in general, about the problem of electric circuits is an exciting and innovative perspective [4]. The diffusion of precepts, via VR, can perhaps help and also provide students with a clearer interpretation and a deeper understanding of the rules [11].

Because the desktop VR applications are reusable and easily updated, they can potentially reduce the budgets in training and can be distributed via the web, ultimately becoming a very attractive option for education and industry. Virtual reality provides an opportunity to deepen understanding, on the part of students, raises awareness about the procedures, and trains students to interact with the equipment [5]. The VEMA prototype application addresses these issues and highlights the potential benefits of the use of VR for this purpose [8].

Each experiment should provide technical/scientific knowledge in order to provide the student/user with the knowledge/experimentation in the syllabus. Virtual trials do not have to be sequential but the sequence of work can help students to learn about the full contents of the syllabus.

Currently there aren't known many organizations or training schools, using virtual reality in this way. One of the goals of this study is to highlight the potential that VR offers the institutions with regard to improved understanding of electrical circuits. If-VR can enhance the effect of learning, it could be argued that, through greater understanding, VR can lead to greater adherence to standards and, consequently, an overall improvement in security in the handling of electrical circuits and equipment in the laboratory environment.

The importance of this work is stressed by its interdisciplinary character as three distinct areas are interrelated: Electrical Measurements, widely used in laboratory environment and stimulating students to learn more about this subject; Mathematics, allowing to characterize and understand the physical phenomena present in the LO; and Computer Science, an area that promotes understanding of the subjects because it facilitates the understanding of contents of Electrical Measurements, Circuit theory and Mathematics, its visualization, and interaction with the student.

VEMA is an application built using a VR desktop system and designed to improve training and the practical performance in a laboratory environment. It enables the "navigation" within a virtual environment and interaction with some electrical components. No browser plug-in is required to view the presentations. WireFusion is a Java applet which is downloaded to the user's browser, as well as other files on the web server, using the HTTP protocol [14].

As a pedagogical instrument, it is a student-centered approach where they can self-learn and investigate the results of their own data in their own time [18].

The VEMA prototype is in its initial phase and undergoing a thorough evaluation of its system.

\section{REFERENCES}

[1] Ruplis,A., Priednieks, E. 2006. Recent Development of Some Learning Tools for Course. Electrical Engineering and Electronics, ISSN 1392 1215, Nr. 7, Page(s): 71.

[2] Silva, M. G. da, Fernandez, M. A. 2007. Recursos informáticos projetados para o ensino de ciências: bases epistemológicas implicadas na construção e desenvolvimento de objetos de aprendizagem. In Objetos de Aprendizagem: uma proposta de recurso pedagógico. Brasília: MEC, SEED, ISBN: 978-85-296-0093-2, Page(s): 27-37 (in Portuguese).

[3] Hong-liang, G. and Shengman, L. 2009, Virtual Reality Technology and its Application in Prevention of Coal and Gas Outburst. In Second International Conference on Information and Computing Science, Manchester, Page(s): 110-113.

[4] Dong Z., Lucas, J. and Thabet, W. 2009. Using virtual environments to support electrical safety awareness in construction. In Proceedings of the 2009 Winter Simulation Conference, Page(s): 2679 - 2690.

[5] Perez, B. Z., Marin, M. M., and Perez, E. I. 2007. Developing a Virtual Environment for Safety Training. In Electronics, Robotics and Automotive Mechanics Conference, Morelos, Page(s): 545 - 550.

[6] Lima, I. S. L.; Carvalho, H. A. DE; Schünzen Junior, K. ; Schlünzen, E. T. M., 2007. “Criando Interfaces para Objetos de Aprendizagem.” Em Prata, C.L. Nascimento, A.C.A. (orgs). Objetos de aprendizagem: uma proposta de recurso pedagógico. Brasília: MEC, SEED, p. 39-48.

[7] Valdez, M. M. Travassos, Ferreira, C. M. Machado and Maciel Barbosa, F. P. 2010. Ferramenta Computacional Educativa para Simulação de Circuitos Eléctricos. INTERTECH'2010, XI International Conference on Engineering and Technology Education, Ilhéus, Baía, Brasil. (in Portuguese).

[8] Valdez, M. M. Travassos, Ferreira, C. M. Machado and Maciel Barbosa, F. P. 2012. Software Packages to Support Electrical Engineering Virtual Lab. International Journal on Emerging Technologies in Learning, iJOE2012. ISSN: 1861-2121. Volume 8, Special Issue 2: exp.at'11, Page(s): 19-23, Special Focus Papers.

[9] Valdez, M. M. Travassos, Ferreira, C. M. Machado and Maciel Barbosa, F. P., 2011. 3D Virtual Labs for Internet Application. IEEExplore2011. International Journal of Online Engineering, iJOE.

[10] Sulbaran, T. and Shiratuddin M.F., "A Proposed Framework for a Virtual Reality Training Tool for Design and Installation of Electrical Systems", in 6th International Conference of Construction on Construction Applications of Virtual Reality, Orlando, Florida, 2006.

[11] Elinda Ai-Lim Lee, Wong Kok Wai, and Chun Che Fung 2010. How does desktop virtual reality enhance learning outcomes? A structural equation modeling approach. Computers \& Education, vol. 55, Page(s): 1424-1442.

[12] 3ds Max. Autodesk ${ }^{\circledR}$ 3ds Max Design ${ }^{\circledR}$. Available from: http://usa.autodesk.com/3ds-max/\#. [Accessed June 10, 2012].

[13] VizUp., VizUp, software company - Optimize 3D models. Available from: http://www.vizup.com/index.html [Accessed April 2012].

[14] WireFusion. WireFusion - Realtime interactive 3D for internet marketing, 3D configurators and product visualizations, 2009, Available from http://www.demicron.com/wirefusion/ [Accessed June 27, 2012].

[15] Balbed, M. A. M., N. Ibrahim, and A. M. Yusof 2008. Implementation of Virtual Environment Using Virtools. Computer Graphics, Imaging and Visualisation. CGIV '08, Fifth International Conference, Page(s): 101 - 106.

[16] Barney Dalgarno and Mark, J.W. Lee 2010. What are the learning affordances of 3-D virtual environments?. British Journal of Educational Technology, vol. 41, no. 1, Page(s): 10-32.

[17] Adamo-Villani, N., Johnson, E. and Penrod, T., "Virtual Reality on the web: the 21st Century World project," in International Conference on Multimedia and Information and Communication Technologies in Education, Lisbon, 2009.

[18] Hsiu-Mei Huang, Ulrich Rauch, and Shu-Sheng Liaw 2010. Investigating learners' attitudes toward virtual reality learning environments: Based on a constructivist approach. Computers \& Education, vol. 55, no. 3, Page(s): 1171-1182. 